\title{
Student Perception as a Planning Input in a Project-Based Construction Pro- gram
}

\section{Dr. Saeed Rokooei, Mississippi State University}

Saeed Rokooei is an assistant professor of Building Construction Science at Mississippi State University. Saeed obtained his bachelor's degree in Architecture and then continued his studies in Project and Construction Management. Saeed completed his $\mathrm{PhD}$ in Construction Management while he got a master of science in Management Information Systems. He is continuing his research on simulation to provide a comprehensive supplementary method in construction management education. 


\title{
Student Perception as a Planning Input in a Project-Based Construction Program
}

\author{
Saeed Rokooei, Ph.D., PMP and Greg Hall, Ph.D., AIA, NCARB \\ Mississippi State University
}

\begin{abstract}
This paper addresses the results of the first stage of a study that explores different factors impacting students' perception in a construction program that presents content through an innovative curricular model — studio-based learning. While there are disciplines outside of those that traditionally embrace studio-based learning such as architecture, art, and design, the application of this method to construction is limited. The similarity of learning objectives such as critical thinking, problem-solving, and collaboration across disciplines to produce buildings provide a strong foundation for applying studio-based learning to construction. While many aspects of architecture studios can be translated and implemented into the construction curriculum, neglecting inherent features of construction education endangers the potential to maximize the potential of this innovative curricular model to achieve effective construction learning. These features include physical, structural, and cognitive aspects of construction curricula necessitated by studio-based learning. In this environment, student perception and feedback can be utilized as a valuable input to regulate the learning system and increase its effectiveness. This paper summarizes quantitative research that was conducted in fall 2017 to investigate how different aspects of studio impact students' perception. This paper explores how students perceive the time structure and layout of the studio space. The results indicate that students perceive various aspects of studio positively, however, their perceptions toward some factors may vary by academic class level. These results are significant because they indicate that students perceive different layouts of studio differently. Modifying the planning and organization of studios ensure that the learning methods and environment support the objectives of the program.
\end{abstract}




\section{Introduction}

Student perception is a major factor that influences the success and outcomes of educational experiences. The ability of faculty to anticipate student perception, appreciate them, proactively manage them in a positive and effective way, and modify the education program accordingly can be a major determinant of student success. This paper addresses ways in which student perception of project-based learning - a unique pedagogical approach to construction education - can be a critical factor that contributes to their success. This paper also outlines ways in which faculty can exploit and plan the educational structure, materials, and methods of studios to manage project-based learning accordingly. Studios are the core components of programs on the design-side of building professions; architecture, interior design, and landscape design programs are historically based on the studio model of education. However, studio-based curricula are an anomaly in construction education; there are only two construction programs in the U.S. with a studio- or project-based curriculum. Despite this, construction management programs present an ideal environment in which to apply the studio pedagogical model. The complexity of the construction industry and its processes and the fact that project-based learning is appropriate to a process that requires multiple players to collaborate to design, create, produce, and provide physical buildings underscores the appropriateness of this educational model. Studios are based on several key unique characteristics of their relative professions. These features range from professional socialization to critical thinking. They require that students engage in in-depth analysis of problems and apply creativity, critical thinking, problem-solving, collaborative interaction, negotiation, and teamwork to achieve satisfactory outcomes. Studioand project-based learning provides a way to increase the relevance of course content by requiring that students not only synthesize information but apply it to actual projects. It also requires that they engage in an iterative process that necessitates reflection as well defense. Finally, in many cases, the studio replicates the collaborative environment in which students will enter as professionals.

The Building Construction Science program at Mississippi State University is a comprehensive studio-based curriculum at all four years. Through a sequence of eight studios, students are introduced to a variety of subjects such as materials and methods, estimating, scheduling, safety, building codes, contract negotiation, and construction law. Project management serves as the 
core concept of the curriculum and unifies these subjects throughout the program. Although each studio focuses on a limited scope of construction education, the intertwined nature of projects addressed in each studio allows these and other various subjects to be integrated and reiterated through different formats. Constant interaction between students and faculty is a key element of their success. This interactive is supported by studio enrollment that is capped at 20 students per faculty member; average studio enrollment is 15 students per faculty member, it is also supported by the studio duration. Each studio is six semester credit hours and meets for a total of 12 hours each week. These curricular factors ensure that effective mutual communication supports achievement of learning objectives. In order to have a better understanding of construction students' perceptions toward the studio-based method, a quantitative research study was designed and performed in the Fall Semester 2017. Ninety percent of second, third, and fourth-year students, all with prior studio experience in the program, participated in the survey to provide their perception. Students in the first year of the program who had no prior student experience also responded to a separate survey that designed to solicit their response. The results of the study indicate ways in which students perceive different aspects of studios and which factors are most important to them in their educational experience. Their responses provide important feedback on ways in which the studio curriculum can be further modified to ensure its effectiveness and appropriateness to the discipline of construction management. Students' perceptions and observations about the studio-curriculum and the benefit to their educational experience provides valuable important information for faculty to consider as they further develop programs to expand the relevance of pedagogy by incorporating project-based learning at any scale. It also provides direction on ways in which faculty and programs can better understand and respond to the gaps between students' perception of education programs and objectives - critical factors in dynamic educational environments of today's institutes of higher education.

\section{Literature Review}

Studios are the core component of architecture programs. The history of studio-based learning in American architecture education extends back to the beginning of the twentieth century when architecture programs were modeled after the famous Ecole des Beaux Arts in Paris, which was served as their benchmark in architectural training (Lackney, 1999). The features and 
characteristics of the studios in the Ecole des Beaux Arts and today's studios include the same key components: a design project, which is the main educational element; a standard number of students (about 20); furniture and furnishings such as tables, papers, books, and models; and a space which accommodates students for majority of their time (Schon, 1983). Studio-based learning has become the backbone of architecture education as well as related disciplines such as art and interior design; rarely do these disciplines deviate from this format. In recent years, studio-based learning has been adopted by other disciplines outside or architecture, art, and design. There are instances that various programs such as computer science and information technology have incorporated studio-based learning in their curricula (Carbone, Lynch, Arnott, \& Jamieson, 2000; Jabi, Hall, Passerini, Borcea, \& Jones, 2008; Mathews, 2010). Although construction is allied with architecture due to its focus on the process of building, studio-based learning has not been implemented in construction education. Despite this, the nature of construction industry, delivery methods, collaborative and interdisciplinary subjects, and similar educational objectives make it an ideal environment in which to apply studio-based learning. Similarities between architecture and construction provide opportunities to translate studio-based learning method from architecture to construction as long as the inherent features and identify of construction programs is considered and carefully addressed to ensure the effectiveness of studio-based learning in a new discipline.

One distinct feature of studio is the meeting time. Along with a relatively high number of credit hours in each studio, meeting time to credit hour ratio, and time required outside the class for projects, studios require a large portion of student time. Many studies have shown that attendance of students is positively correlated with the performance and final grades (Lukkarinena, Koivukangasa, \& Seppälä, 2016). In a study exploring the causal impact of instruction time on student test scores, Cattaneo, Oggenfuss, and Wolter (2016) reported that students differed substantially in the time needed to learn and the effectiveness of instructional time between different schools is considerably different. Ewer, Greer, Bridges, and Lewis (2002) compared two traditional courses with shortened versions of those at Southwest Missouri State University and concluded that students in these two different settings had similar performances. In a similar study, Gamboa (2013) analyzed student performance over five years to explore the impact of course length on course success. Analysis showed that students in condensed courses 
were more likely to be successful than students in traditional length courses. This finding was consistent with what Sheldon and Durdella (2010) stated as students were more successful in compressed-format courses than those enrolled regular-length courses. Austin and Gustafson (2006) used a database of over 45,000 observations and reported that intensive courses result in higher grades than traditional courses. Carrington (2010) examined four different schedules and stated that while there is no difference between the performance of students in compressed or intensive (one-day per week) schedules and a two-day per week schedule, the success of students was significantly lower in the three-day per week schedule than other schedules. In addition, some researchers have shown how a particular time of day can impact student performance. For example, Goldstein et al. (2007) and Shapiro and Williams (2015) reported that test scores are significantly lower during the early morning hours for adolescents.

\section{Methodology}

The main objective of this study was to understand the perception of students toward the cognitive and physical environment in studios. Based on the nature and comprehensive scope of the subject, a quantitative research methodology was used. To obtain feedback and input from students, a survey was designed and administrated in Fall Semester 2017 for the first phase of this study. Questions in the survey were designed to obtain responses about the spatial and temporal aspects of studios:

- How do different physical features of studio impact students' perceptions?

- How do students perceive their current time layout and how is it compared with other alternatives?

- Is there any relationship between the students' time layout preferences and their current status?

Because the focus of the survey was the student's perception of the studio experience, other aspects of the program were not included in the survey. The survey was distributed by paper to allow students to increase interaction with the researcher and to remove possible ambiguities while answering the questions. A sample of 74 undergraduate construction students, including 19 senior, 25 junior, and 30 sophomore students, participated in the study. This ensured that every respondent had the experience of at least three semester-long studios. Data was then gathered, 
compiled, coded, and analyzed using statistical software. The results, which provided new unforeseen insights into the studio curriculum, are described in the next section.

\section{Results}

From the sample size of 74 students, 93\% reported as male respondents. The average work experience of the sample was reported 21 months which can be divided into 10, 15, and 27 months of experience for sophomore, junior, and senior students, respectively. Students were also asked to report their overall GPA and the average of their studio grades. On average, the overall GPA reported was 3.06; the studio average GPA was 3.46. It should be noted that, based on the department regulation, each studio includes a prerequisite that the students' institutional GPA must be at least 2.00. Students with an institutional GPA less than 2.0 are not allowed to take a studio until they have raised their institutional GPA. Figure 1 shows the percentage of each letter grade for overall and studio GPA.

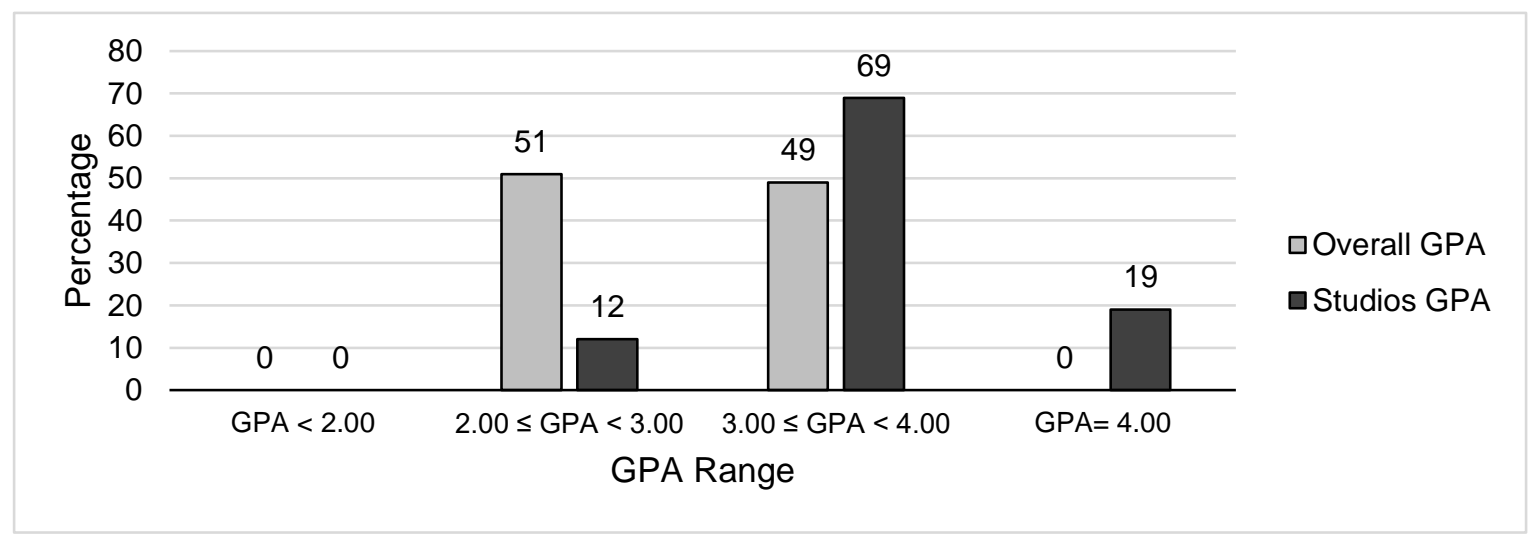

Figure 1: Overall GPA and Studios GPA of Students

The current curriculum of Building Construction Science program at Mississippi State University includes eight studios, each semester-long studio is six credit hours or 12 hours of studio meeting time each week. Through a Likert Scale question, students were asked to what extent they think studio meeting time (12 hours/week) is appropriate. Five levels of answers were "Absolutely inappropriate," "Inappropriate," "Neutral," “Appropriate," and "Absolutely appropriate." The majority of students did not think the current 12 hours of studio meeting time is appropriate (Absolutely inappropriate: $27 \%$, and Inappropriate: $39 \%$ ) and only $16 \%$ of 
respondents believed the current meeting time is favorable (Appropriate: 12\% and Absolutely appropriate: $4 \%$ ), and $18 \%$ of all were neutral. Figure 2 shows the percentage of each level among three groups of sophomore, junior, and senior students.

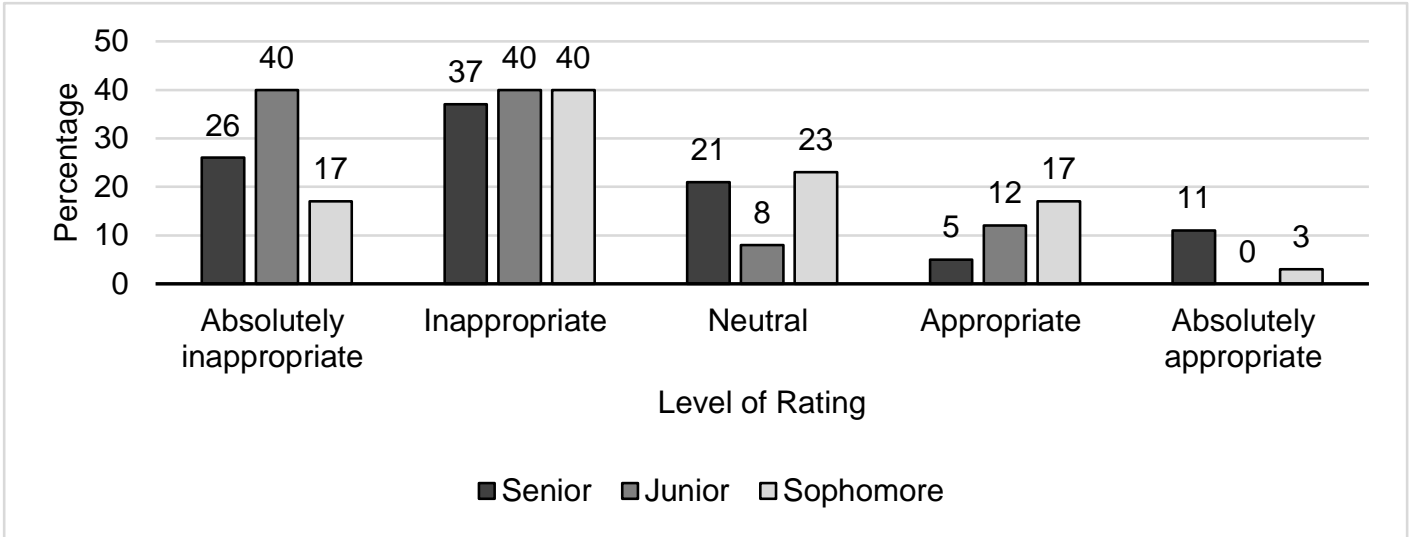

Figure 2: Percentage of levels of appropriateness for each class group

Students were asked to report their level of engagement, Not engaged: 3\%, Slightly engaged: 20\%, Moderately engaged: 36\%, Engaged: 32\%, and Very engaged: $9 \%$. No significant correlation was found between the level of engagement and current studio meeting time. In the next section, students were asked how many hours on average they spend on their studios outside the meeting time. Figure 2 shows the percentage of each category for the number of hours reported by students. On average, students reported spending 12 hours outside of meeting time on their studio projects.

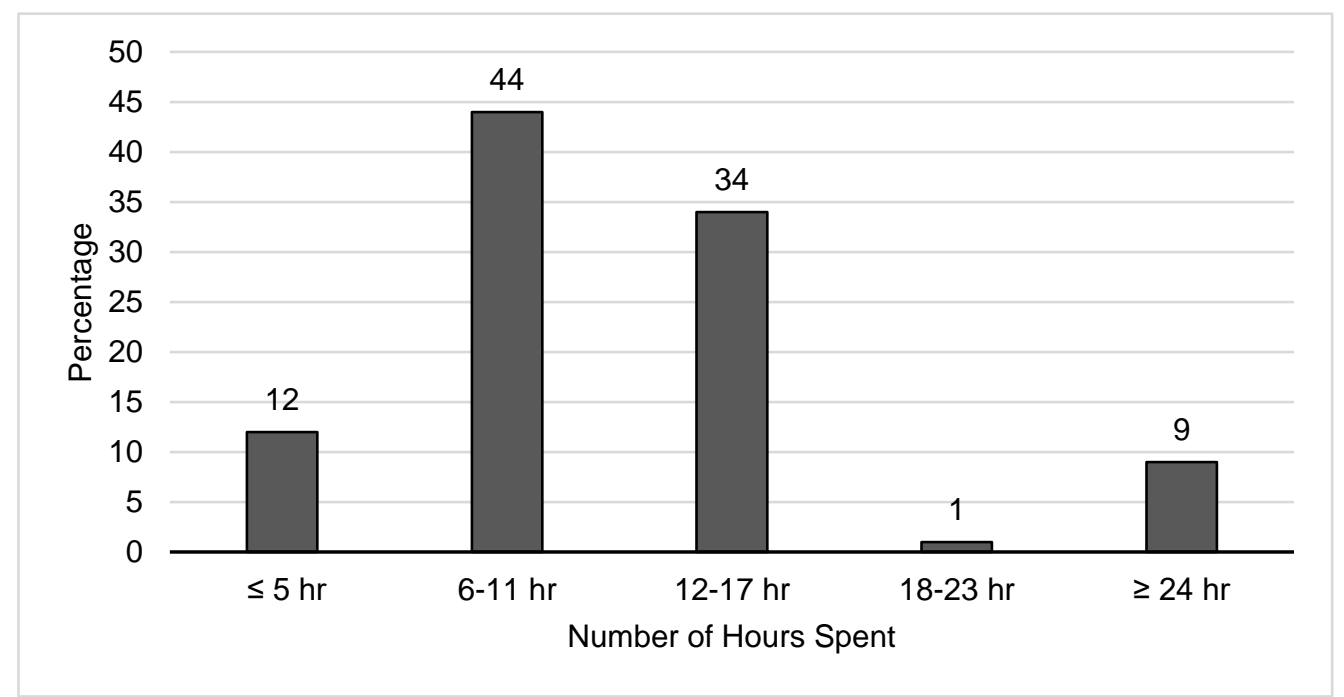

Figure 3: Reported number of hours spent outside the class 
In the next section, students were asked to specify how they would like to see their time being divided into subjects and activities. Three possible situations were provided. These situations and related percentages are provided in Table 1.

Table 1: Percentage of each possible situation in studio

\begin{tabular}{|l|c|}
\hline \multicolumn{1}{|c|}{ Studio Activities } & Percentage \\
\hline Working on one large project throughout the semester & $28 \%$ \\
\hline Working on a few shorter projects and examples that are related to each other & $57 \%$ \\
\hline Working on a few unrelated shorter projects & $15 \%$ \\
\hline \multicolumn{1}{|c|}{ Total } & $100 \%$ \\
\hline
\end{tabular}

Students were also asked to divide the studio time into three possible instructor-student interactions including "One-on-one discussions with students," "Discussions and interactions with each group/team," and "Class presentations/General discussions." The average percentages for these groups were 28, 39, and 33, respectively. In the next step, respondents were compared based on their class level. The percentage of each possible situation in studio (described in Table 1) for each class level and studio GPA level is shown in Figure 4 and Figure 5.

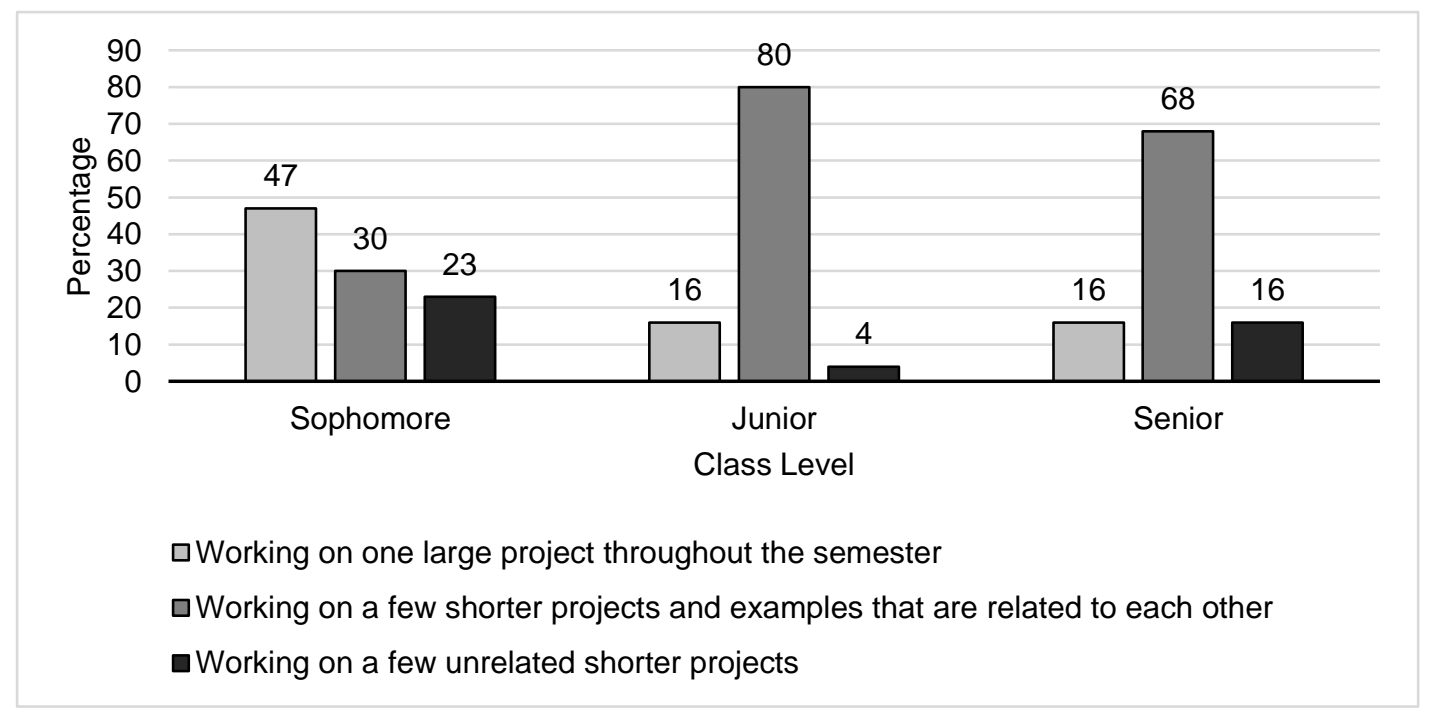

Figure 4: Percentage of preferred activities in studio by each class level 


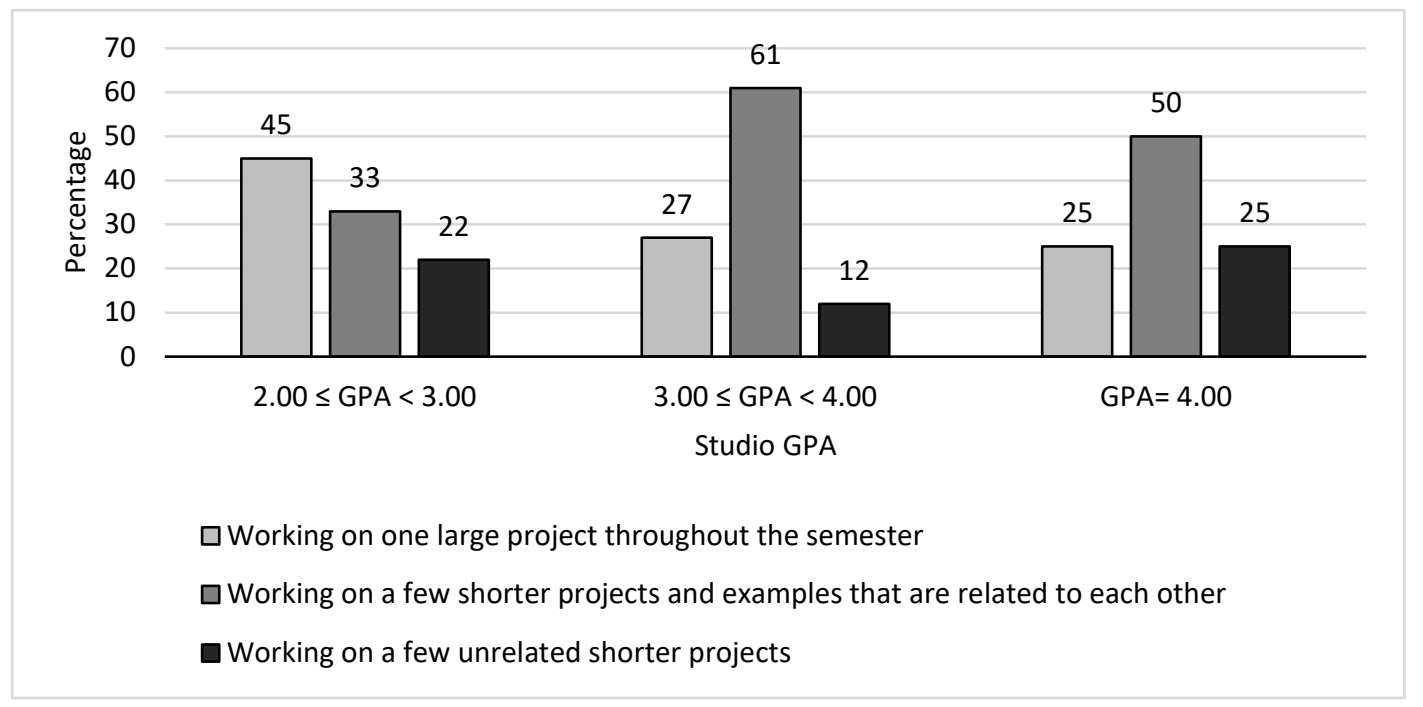

Figure 5: Percentage of preferred activities in studio by each studio GPA level

The percentage of each of three possible instructor-student interactions at each class level in Table 2.

Table 2: Percentage of preferred instructor-student interaction by each class level

\begin{tabular}{|c|c|c|c|}
\hline Instructor-student interaction & Sophomore & Junior & Senior \\
\hline One on one discussions with students & $32 \%$ & $21 \%$ & $30 \%$ \\
\hline Discussions and interactions with each group/team & $36 \%$ & $44 \%$ & $34 \%$ \\
\hline Class presentations/General discussions & $30 \%$ & $35 \%$ & $36 \%$ \\
\hline Total & $100 \%$ & $100 \%$ & $100 \%$ \\
\hline
\end{tabular}

Currently, all studios in the Building Construction Science program are offered on Monday, Wednesday, and Friday from 1:00 to 5:00 pm. To understand how this schedule is perceived, students were asked to rate the desirability of four possible option including the current one. Those four options were as follows:

- Option A: Current structure

- Option B: Monday, Wednesday, Friday- 8:00 am - 12:00 pm

- Option C: Monday \& Wednesday 12:00 pm - 6:00 pm

- $\quad$ Option D: Monday \& Wednesday 7:00 am - 1:00 pm 
Each of five levels of desirability from "very undesirable" to "very desirable" was quantified to 1-5, respectively. The average score of options A-D was 2.64, 2.62, 3.23, and 2.30, respectively which indicates a similar medium desirability between Option A and Option B. In addition, Option C was reported as the favorite option while Option D was rated as the least favorite option. Figure 6 shows the percentage of each option at each desirability level.

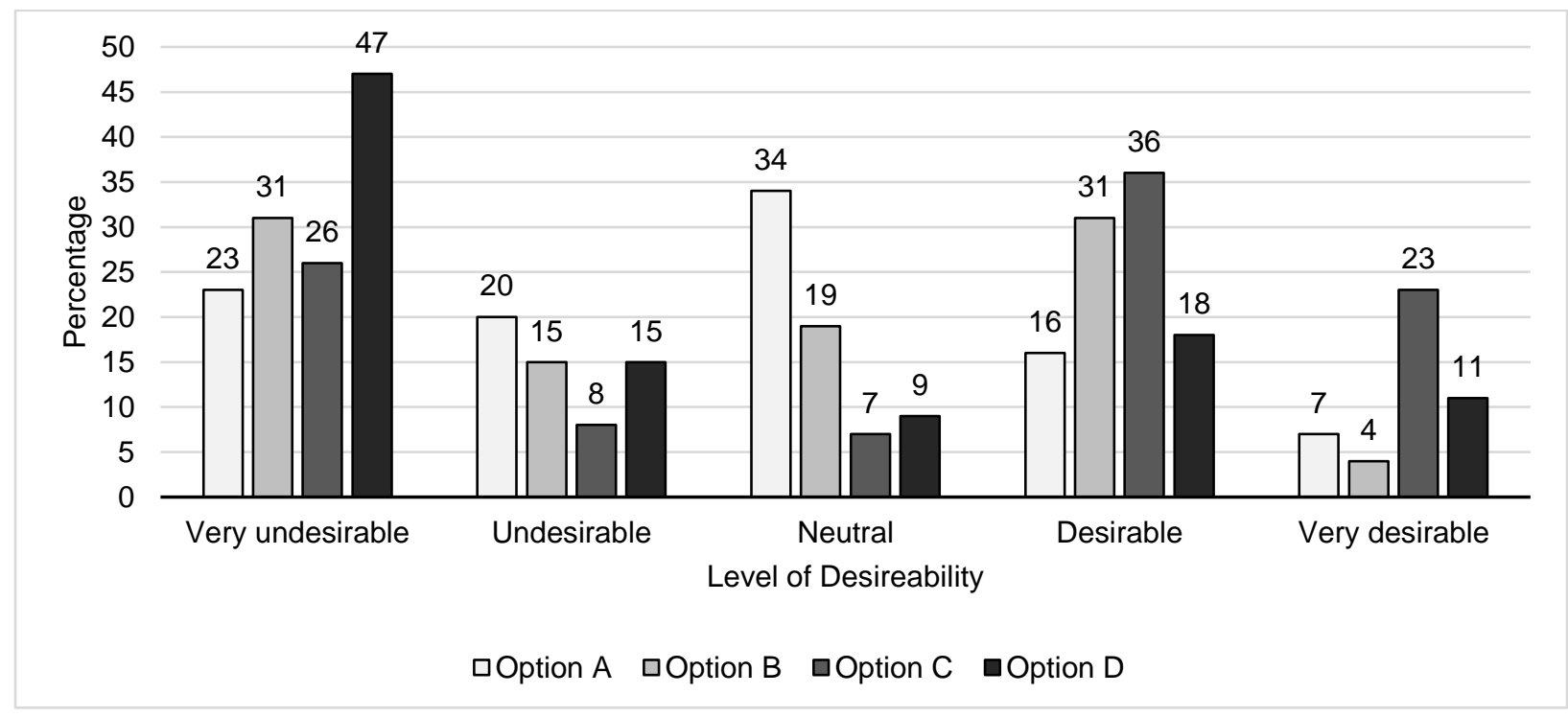

Figure 6: Percentage of each level of desirability for possible timing options

In the next section, a few more options were provided to students and they were asked to rate to what extent these new options are desirable. In this stage, the variable was assumed to be the number of credit hours for the studio. As mentioned before, each studio is six credit hours. By changing the number of credit hours to five, it would be possible to offer two additional conventional courses (either in the area of engineering or architecture) during the four years of the program and maintain the current 124 semester credit hours. These options are as follows:

- Option I: Studios Each 6 credit hours (current structure)

- Option II: Studios Each 5 credit hours M-W Morning + 2 Engineering courses

- Option III: Studios Each 5 credit hours MW Afternoon + 2 Engineering courses

- Option IV: Studios Each 5 credit hours MW Morning + 2 Architecture courses

- Option V: Studios Each 5 credit hours MW Afternoon + 2 Architecture courses 
Likewise, each level of desirability from "very undesirable" to "very desirable" was quantified to numbers 1-5, respectively. The average score of each option and the percentage of each level is shown in Table 3.

Table 3: Percentage of each level of desirability for each option

\begin{tabular}{|l|c|c|c|c|c|}
\hline & Option I & Option II & Option III & Option IV & Option V \\
\hline Very undesirable (\%) & 4 & 15 & 12 & 31 & 24 \\
\hline Undesirable (\%) & 11 & 26 & 18 & 19 & 22 \\
\hline Neutral (\%) & 47 & 32 & 34 & 19 & 32 \\
\hline Desirable (\%) & 26 & 19 & 24 & 27 & 19 \\
\hline Very desirable (\%) & 12 & 8 & 12 & 4 & 3 \\
\hline Total (\%) & 100 & 100 & 100 & 100 & 100 \\
\hline Average (out of 5) & 3.31 & 2.80 & 3.07 & 2.54 & 2.54 \\
\hline
\end{tabular}

Finally, students were asked what the optimum number of hours per week for studio meeting time is. The overall average of all students was 8.38 hours. Similarly, the average of proposed number for sophomore, junior, and senior students was 8.34, 8.00, and 8.94, respectively.

\section{Discussion}

Although the studio-based curriculum is not a new learning method in higher education, a limited number of programs outside of design professions that have traditionally employed studio-based methods have embraced this model. Architecture and similar art-based programs typically use studios as the core components of their curricula; it would difficult to imagine an architecture program without studio learning. Due to the predominance of this model and the relative lack of deviation from it among architecture, art, and design disciplines, incorporation of studio learning in other disciplines has relied on this long-standing precedent with little deviation.

While there are many similarities between architecture and construction programs, substantial distinctions among these two should not be overlooked. If these differences and distinctions are not properly addressed, there is a risk of missing inherent features and characteristics of construction education. While there are insufficient examples of best practices in construction 
education to serve as a benchmark for conventional construction programs, the perceptions of construction students who have experienced any type of studio can be considered as a valuable input. However, the paucity of information is not the only reason to use students' perceptions. It has been shown that students' perceptions in educational setting directly impact their performance (Russell Calk, 2006; Ferreira \& Santoso, 2008; Ma, Chen, \& Ampountolas, 2016). This study strives to explore different factors impact students' perceptions. These factors can be categorized into physical and non-physical factors. Many research studies have shown how different factors affect students' perceptions (Hill \& Epps, 2010; Yildirima, Capanoglub, \& Cagataya, 2011; Asiyai, 2014; Wayne, Fortner, Kitzes, Timm, \& Kalishman, 2013; Samdal, Wold, \& Bronis, 2010; Joanna, 2009). Among the factors affecting students' perceptions, those which focus on the time structure and layout of studio are discussed in this paper. While the ratio of studio meeting time per credit hour is uniformly applied by the university and it is quite consistent among all higher education institutes, students perceived the current meeting time as not appropriate. Two third of students rated the current 12 hours of studio meeting time as either absolutely inappropriate or inappropriate. In contrary, only one-sixth of students rated current structure as absolutely appropriate or appropriate. This should further discussed if the architecture-based credit hour to studio meeting time model ratio of 1 to 2 is still an effective ratio for construction studios. Also, it should be noted that the percentage of "Absolutely inappropriate" level for sophomore students who are typically more involved in hands-on experiences is considerably lower than that of junior or senior students who are not generally involved in physical activities and instead focus on managerial subjects of construction contents. Moreover, students reported that they spend 12 hours, on average, for their studio-related activities outside the meeting time. While there are different options concerning activities that students can perform in their studio, the majority of students preferred to be involved in a few related projects throughout the semester. This is unlike architecture program in which there is typically one major project each semester defined for students. However, this pattern in construction students varies from lower levels to upper levels as students in upper levels are more willing to perform a few shorter projects. In addition, the preference of one-to-one discussions will be lower in upper levels while studio presentations and discussions will be more favorable. Another noticeable issue with the results is the studio meeting days. Based on the results, two general points can be inferred. Students preferred the two-day schedule over the 
three-day one. Early morning classes are not as favorable as afternoon ones. In addition, six credit hours for each studio is perceived as a reasonable number of credit hours. However, if there is need to reduce the total number of current studio credit hours and add two courses construction students were receptive to adding an engineering course than an architecture course.

\section{Conclusion}

This paper addressed the results of the first stage of a research project that aims to investigate studio-based curriculum in construction programs and the way students perceive the new educational model. Among the factors impacting students' perceptions, those that are related to time structure and layout of studios in construction program are discussed in this paper. Overall, as shown in Figure 1, the higher GPA of students in studios compared with overall GPA indicates students' enthusiasm for their studio-based curriculum which is consistent with their reported level of engagement. While students on average did not show their consent regarding the current 12 hours of meeting time for their studios, no significant correlation was found between the level of engagement and current studio meeting time. Thus, a different studio meeting time structure or better use of time in studio can be assumed without any engagement concern. The total of 24 hours of inside and outside studio work for a six-credit hour course indicates an ample amount of time that students typically spend. This is consistent with an optimistic number of hours recommended to students in lecture-based courses.

One issue that construction educators and administrators encounter in studio-based models is planning for a relatively high number of studio meeting times and days. For example, dividing 12 hours of studio meeting time into three days per week prohibits using the other two remaining days for a similar studio meeting schedule. However, providing required studio time into two days increases the flexibility of educators to have studios meet either Monday and Wednesday or Tuesday and Thursday, which is more favorable to students as well. While this paper reported the perceptions of the majority of students in a studio-based construction program, generalization of outcomes is not warranted and would necessitate further investigation. More qualitative and quantitative studies with larger samples are required. Incorporating the insight of industry and construction faculty community toward the studio-based model will enhance the results of this study and the application of its findings. 


\section{References}

Asiyai, R. (2014). Students' Perception of the Condition of Their Classroom Physical Learning Environment and Its Impact on Their Learning and Motivation. College Student Journal, 48(4).

Austin, A. M., \& Gustafson, L. (2006). Impact of Course Length on Student Learning. Journal of Economics and Finance Education, 5(1), 26-37.

Carbone, A., Lynch, K., Arnott, D., \& Jamieson, P. (2000). Introducing a studio-based learning environment into Information Technology. Flexible Learning for a Flexible Society. Toowoomba: University of Southern Queensland.

Carrington, L. G. (2010). The Impact of Course Scheduling on Student Success in Intermediate Accounting. American Journal of Business Education, 3(4), 51-60.

Cattaneo, M. A., Oggenfuss, C., \& Wolter, S. C. (2016). The More, the Better? The Impact of Instructional Time on Student Performance. Bonn, Germany: IZA Institute of Labor Economics.

Ewer, S., Greer, O., Bridges, W., \& Lewis, B. (2002). Class Length and Student Performance: An Extended Study. International Advances in Economic Research, 160-168.

Ferreira, A., \& Santoso, A. (2008). Do students' perceptions matter? A study of the effect of students' perceptions on academic performance. Accounting and Finance, 48, 209-231.

Gamboa, B. R. (2013). Impact of Course Length on and sebsequent Use as a Predictor. Institutional Research, Effectiveness, and Planning. Crafton Hills College, Yucaipa, CA.

Goldstein, D., Hahn, C., Hasher, L., Wiprzycka, U., \& Zelazo, P. D. (2007). Time of Day, Intellectual Performance, and Behavioral Problems in Morning Versus Evening Type Adolescents: Is There a Synchrony Effect? Personality and Individual Differences, 42(3).

Hill, M., \& Epps, K. (2010). The Impact of Physical Classroom Environment on Student Satisfaction and Student Evaluation of Teaching in the University Environment. Academy of Educational Leadership, 14(4), 65-79.

Jabi, W., Hall, T., Passerini, K., Borcea, C., \& Jones, Q. (2008). Exporting the Studio Model of Learning - Teaming Architecture with Computer Science. Proceedings of the 26th Conference on Education and Research in Computer Aided Architectural Design in Europe (pp. 509-516). Antwerp, Belgium: Education and Research in Compuater Aided Architectural Design in Europr (ECAADE).

Joanna, I. O. (2009, December). Relationship Between Students' Perception of Classroom Psycho-social Environment and Achievement in Geography. Dissertation. University of Nigeria, Nsukka, Nigeria.

Lackney, J. A. (1999). A History of the Studio-based Learning Model. Retrieved from http://edi.msstate.edu/work/pdf/history_studio_based_learning.pdf

Lukkarinena, A., Koivukangasa, P., \& Seppälä, T. (2016). Relationship between class attendance and student performance. 2nd International Conference on Higher Education Advances (pp. 341347). València, Spain: Procedia - Social and Behavioral Sciences. 
Ma, Z., Chen, M.-H., \& Ampountolas, A. (2016). The Effect of Students' Perceptions and Learning Approaches on the Quality of Hospitality Financial Management Education. Journal of Hospitality \& Tourism Education, 28(4).

Mathews, J. (2010). Using a Studio-based Pedagogy to Engage Students in the Design of Mobile-based Media. English Teaching: Practice and Critique, 9 (November), 87-102.

Russell Calk, M. J. (2006). How Student Perceptions of Learning Labs Affect Performance in the First Accounting Course. Journal of Business Inquiry, 50-56.

Samdal, O., Wold, B., \& Bronis, M. (2010). Relationship between Students' Perceptions of School Environment, Their Satisfaction with School and Perceived Academic Achievement: An International Study. School Effectiveness and School Improvement, 296-320.

Schon, D. (1983). The Reflective Practitioner: How Professionals Think in Action. New York: Basic Books.

Shapiro, T. M., \& Williams, K. M. (2015). The Causal Effect of the School Day Schedule on the Academic Achievement of Adolescents. Colorado: Society for Research on Educational Effectiveness (SREE).

Sheldon, C. Q., \& Durdella, N. R. (2010). Success Rate for Students Taking Compressed and Regular Length Developmental Courses in the Community College. Community College Journal of Research and Practice, 39-54.

Wayne, S., Fortner, S., Kitzes, J., Timm, C., \& Kalishman, S. (2013). Cause or Effect? The Relationship Between Student Perception of the Medical School Learning Environment and Academic Performance on USMLE Step 1. Medical Teacher, 376-380. doi:10.3109/0142159X.2013.769678

Yildirima, K., Capanoglub, A., \& Cagataya, K. (2011). The Effects of Physical Environmental Factors on Students' Perceptions in Computer Classrooms. Indoor and Built Environment, 20(5), 501-510. 